\title{
Cerebrovascular complications of transorbital penetrating intracranial injuries
}

\author{
Yonca Özkan Arat, M.D., ${ }^{1,2}$ Anıl Arat, M.D., ${ }^{3}$ Kubilay Aydın, M.D. ${ }^{4}$ \\ ${ }^{1}$ Department of Ophthalmology, Baskent University Faculty of Medicine, Ankara \\ ${ }^{2}$ Department of Ophthalmology and Visual Sciences, University of Wisconsin, Madison, WI, USA \\ ${ }^{3}$ Department of Radiology, Section of Interventional Neuroradiology, Hacettepe University Faculty of Medicine, Ankara \\ ${ }^{4}$ Department of Radiology, Section of Interventional Neuroradiology, Istanbul University Istanbul Faculty of Medicine, Istanbul
}

\begin{abstract}
BACKGROUND: Cerebrovascular trauma secondary to transorbital intracranial penetrating injury (TIPVI) is rare. Relatively benign initial presentation may mask the underlying life-threatening vascular injury in transorbital intracranial penetrations. The aim of this study was to evaluate clinical features and endovascular treatment of TIPVI.
\end{abstract}

METHODS: Six patients with angiographic documentation of TIPVI in subacute/chronic phase were reviewed retrospectively. Five were treated endovascularly; however endovascular treatment was aborted in one and conservative management was pursued.

RESULTS: Except for one case presenting with vision loss and mild stroke, no significant neurologic deficit was present. Vascular lesions included two cases of carotid-cavernous fistulas, three traumatic aneurysms of cavernous carotid, anterior and middle cerebral arteries and a unique case of coalescing cavernous aneurysms following a through-and-through injury in which the aneurysms united within the thrombosed cavernous sinus on follow up. Fistulas were treated with covered stents, aneurysms with parent artery occlusion or flow diverters. All patients had uneventful recoveries.

CONCLUSION: TIPVI may present in a delayed fashion after a seemingly benign presentation. A high index of suspicion is critical to rule out TIPVI with vascular imaging. Transcatheter angiographic techniques allow for both diagnosis and treatment of TIPVI with favorable results.

Key words: Cerebrovascular injury; fistula; penetrating intracranial injury; transorbital injury; traumatic aneurysm.

\section{INTRODUCTION}

Penetrating head injuries (PHI) represent about $0.4 \%$ of head injuries. ${ }^{[1]}$ Compared with closed head injuries, PHIs are usually more severe and result in higher mortality and morbidity. $[2,3]$ They have historically been seen in military settings, but over the past two decades, civilian cases of PHI have been reported more frequently. PHls are usually high-velocity type in military settings and low-velocity type including predominantly accidental injuries in the civilian settings. ${ }^{[2,3]}$ Transor-

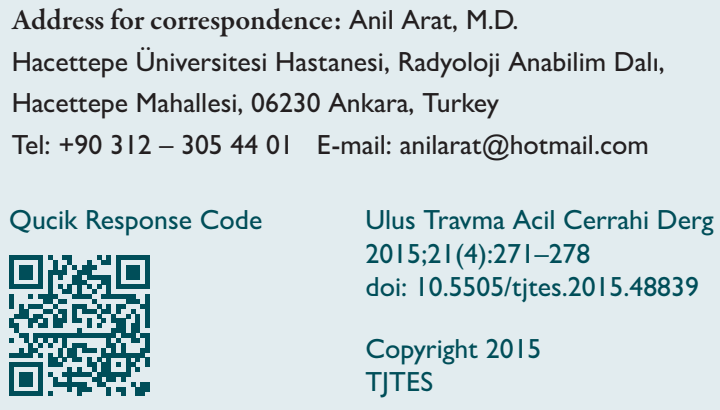

bital penetrating intracranial injury (TIPI) is aparticular type of $\mathrm{PHI}$ in this regard, as the orbit forms a 'low-resistance' pathway for the more commonly encountered low-velocity injuries in daily life. ${ }^{[4]}$ It represents an uncommon type of injury, ${ }^{[5,6]}$ it occurs more frequently in children, ${ }^{[7,8]}$ and its management has been reported to be a challenge. ${ }^{[9]}$

Although uncommon, TIPI may result in grave complications such as cerebrovascular injury, central nervous system infections, cerebrospinal fluid fistulas, and venous thrombosis. [10-12] Among these complications, transorbital intracranial penetrating vascular injury (TIPVI) stands out as a risk factor for imminent death or disability. ${ }^{[13]}$ Very limited data exist regarding the incidence and management of vascular injuries in TIPI. There are only a handful of cases of vascular complications after TIPI described in the literature. Due to their rare occurrence and diversity of mechanisms or patterns of such injury, ${ }^{[14,15]}$ no standards exist regarding the management of these injuries. This series aimed to reviewthe presentation and endovascular management of TIPI cases with vascular complications we encountered, which were treated by neurointerventional procedures. 


\section{MATERIALS AND METHODS}

This manuscript is related to cerebrovascular trauma secondary to low and high velocity transorbital intracranial penetrating injury. TIPI was described by Van Duinen ${ }^{[10]}$ as entry of objects whose diameter is much smaller than the diameter of the anterior orbital opening, from the orbit into the intracranial space. He put forward that the orbital rim should remain intact, and he excluded high velocity injuries although he admitted that a clear cut-off between low and high velocity injuries is not clear. This point is also highlighted by other authors. ${ }^{\left[{ }^{[6]}\right.}$ In his thesis about TIPI, Welman ${ }^{[17]}$ also excluded high velocity injuries but included all penetrating trauma with an object that either traverses or is suspected to have traversed the orbital space. In this article, due to the lack of a clear distinction between high and low velocity impacts, ${ }^{[10]}$ all penetrating injuries were included, provided that there was not extensive craniofacial injury and the penetrating injury primarily involved the compartment bordered by the skull bones forming the orbital walls. In this article, TIPVI is defined as vascular injuries caused by TIPI and includes traumatic aneurysms, caroticocavernous fistulas (CCF), cavernous sinus thrombosis and arterial occlusions. This is a retrospective review of six cases with TIPVI which the corresponding author encountered throughout his practice. In five of these cases, he was the primary operator for the endovascular treatment; however, in one patient, he was involved through case consultation and the third author was the primary interventionist.

All patients had a cerebral digital subtraction angiogram delineating the vascular injury and an endovascular treatment was attempted in all of the patients. Endovascular treatment was performed in all cases under general anesthesia and systemic heparinization via femoral percutaneous approach. In three cases treated by stents (stent grafts or flow diverter stents), patients were loaded with Clopidogrel and Aspirin at least I week prior to the procedure and patients were asked to continue antiplatelet medication for 6 months. For two of these patients who were above $50 \mathrm{~kg}$ (Case 4 and 6), the maintenance dose was $75 \mathrm{mg} /$ day for Clopidogrel, $300 \mathrm{mg} /$ day for Aspirin, and for the third patient who was 4 years old (Case 3) the patients family was asked to give the patient a quarter of a $75 \mathrm{mg}$ tablet of Clopidogrel and $100 \mathrm{mg}$ of Aspirin daily.

\section{RESULTS}

There were a total of six patients (I female, 5 male) with vascular injuries secondary to transorbital intracranial injury. All except one were children; mean age was 13.3 years (range, 2-27 years). Only the adult case had a high-velocity injury (Case 6). Both of the young children (Cases 3 and 5) had an accidental injury with a knitting needle, and all the other patients had an assault with sharp objects or shot guns. One patient (Case 2) had an injury with multiple pellets that passed through both orbits resulting in bilateral open globe injury with no light perception vision. Otherwise, none of the remaining cases had a globe injury. Endovascular treatment was successful in Cases 2 to 6 . In the first patient, it appeared very feasible to finish the endovascular procedure with deployment of a stent during the procedure; however, the patient was noncompliant with medical advice. In order not to put the patient under the risk of a thromboembolic event based on her anticipated noncompliance to antiplatelet medication after discharge, the procedure was aborted and the patient was followed. In four out of six patients (67\%), the involved artery was occluded either intentionally or during follow-up, without any clinical consequences.

The following includes the pertinent findings of patients in this series:

Case I- I5-year-old female was assaulted and presented to the emergency department with a right orbital pellet injury and frontal lobe hematoma. After evacuation of frontal hematoma, based on the initial CT scan which showed a fracture in the right and left nasal superior orbital rim and multiple pellets in the cranium without major injury to the globe, vascular imaging was requested. Since the pellets in close proximity of the ICA precluded a thorough visualization of the artery on CT angiogram, an angiogram was performed to rule out a vascular injury. The cerebral angiogram revealed a 3 $\mathrm{mm}$ bilobulated traumatic cavernous aneurysm. An attempt for primary coiling of the aneurysm failed. Since the patient was not compliant with medical advice and stent placement would entail strict adherence to antiplatelet medication, it was decided not to proceed with stent placement and follow the aneurysm conservatively. One year follow-up angiogram showed a decrease in the size and lobulation of the aneurysm.

Case 2- A 16-year-old male presented to the emergency room after being shot through the orbit with a shotgun. On examination, there was bilateral open globe injury with no light perception vision and orbital soft tissue injury. He was also noted to have pellets in close proximity of the right internal carotid artery (ICA) on CT scan, which prompted a cerebral angiogram. On angiogram, there were 3 tiny aneurysms of the cavernous ICA and no evidence of a carotid cavernous fistula (Fig. Ia). A repeat angiogram obtained after 8 days, on the day of the endovascular treatment of the aneurysms, showed interval enlargement of the aneurysms (Fig. Ib). Selective coiling was attempted, but it was realized that the two of the larger aneurysms had coalesced within the cavernous sinus, still in the absence of a carotid cavernous fistula (Fig. IC). Stent reconstruction of the artery was unsuccessful and based on the presence of very good collateral flow through the Circle of Willis, the patient was treated with parent artery occlusion (Fig. Id). The patient's family denied a follow-up angiogram, patient had no significant neurologic deficits except for bilateral blindness at 6 months.

Case 3-A 4-year-old boy presented to the emergency room after an accidental injury caused by a knitting needle pen- 

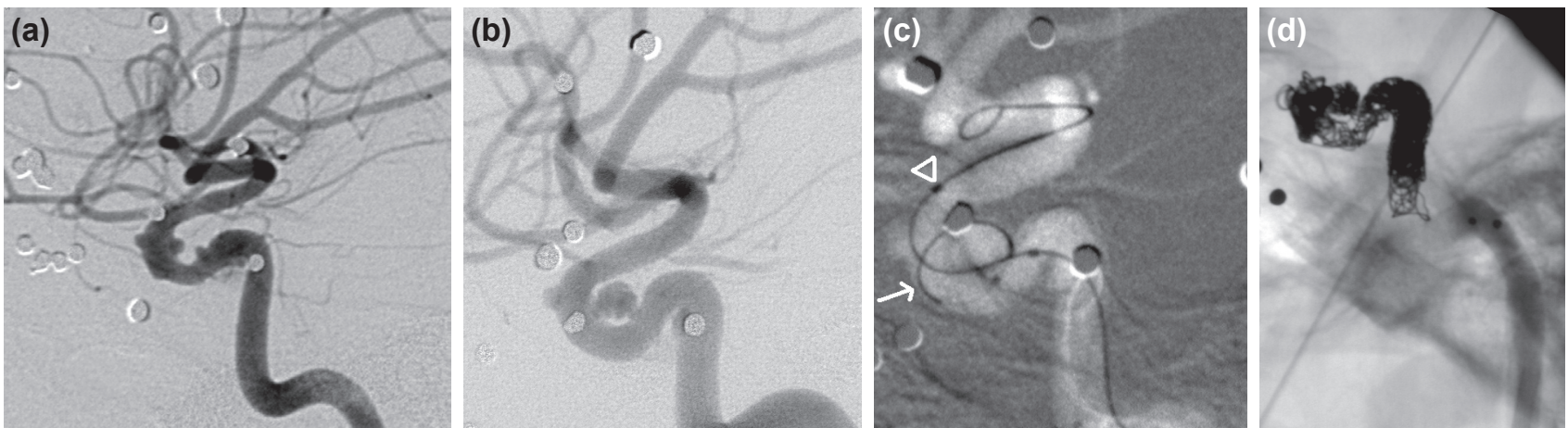

Figure 1. Case 2; (a) Magnified views of the right carotid angiogram in lateral projection obtained after the assault reveals three tiny aneurysms of the cavernous carotid artery measuring approximately 1 to $1.5 \mathrm{~mm}$ in size and mild contour abnormality of the inferior border of the proximal cavernous carotid artery. (b) Follow-up angiogram in lateral view demonstrates interval growth of the aneurysm at the level of the dural ring. The 2 more proximal aneurysms have coalesced into a larger, approximately $5 \mathrm{~mm}$ aneurysm. Although the through-and through injury of the carotid artery involves the cavernous segment no evidence of a fistula at this site is noted. (c) Roadmap capture during embolization reveals that microcatheter used to catheterize the aneurysm (arrow) projecting posteriorly from the genu reentered the internal carotid artery from wall the defect at the orifice of the most proximal aneurysm. A balloon catheter was placed in the carotid artery (arrowhead) to protect the patency of the internal carotid artery but was removed later, upon recognition of the "multihole" injury of the carotid artery. (d) Lateral radiogram at the end of parent artery sacrifice. The carotid artery was coiled first in a retrograde fashion through the microcatheter reentering the artery proximally. As the catheter kicked back into the ICA, coiling was continued to complete occlusion of the carotid artery. An Amplatzer Vascular Plug (St. Jude Medical, St. Paul, MN) was placed proximally and stagnation of the contrast medium below the plug is evident.

etrating the right orbit. The needle was removed at the site of the accident. On examination, the entry wound was noted at the medial canthus. The patient had no neurologic deficit except for right abducence and facial nerve paresis. CT of the head revealed right retroorbital and subarachnoid hemorrhage. Since the patient had right pulsatile exophtalmus and subarachnoid hemorrhage, he underwent a carotid angiogram which revealed a right CCF (Fig. 2a). The patient was treated endovascularly. A detachable balloon was navigated to the site of the fistula and inflated (Fig. 2b). Due to the extent of the tear in the carotid artery, this was not sufficient to seal the site of the fistula. The wall defect was then covered by placement of two $4.5 \mathrm{~mm}$ polytetrafluoroethylene-covered stent grafts (Jomed, Helsingborg, Sweden) at the site of the fistula that resulted in immediate occlusion of the fistula without any procedure related complications (Fig. 2c). Six month follow-up carotid angiography incidentally revealed interval occlusion of the right internal carotid artery and robust collateral flow through the Circle of Willis supplying the right ICA territory.

Case 4- A 16-year-old male was referred with complaints of headache. He had a history of a 'pencil injury' in the classroom three months before the presentation. The pencil entered the orbit superiorly without damaging the globe. There was no neurologic deficit, but the patient had signifi-
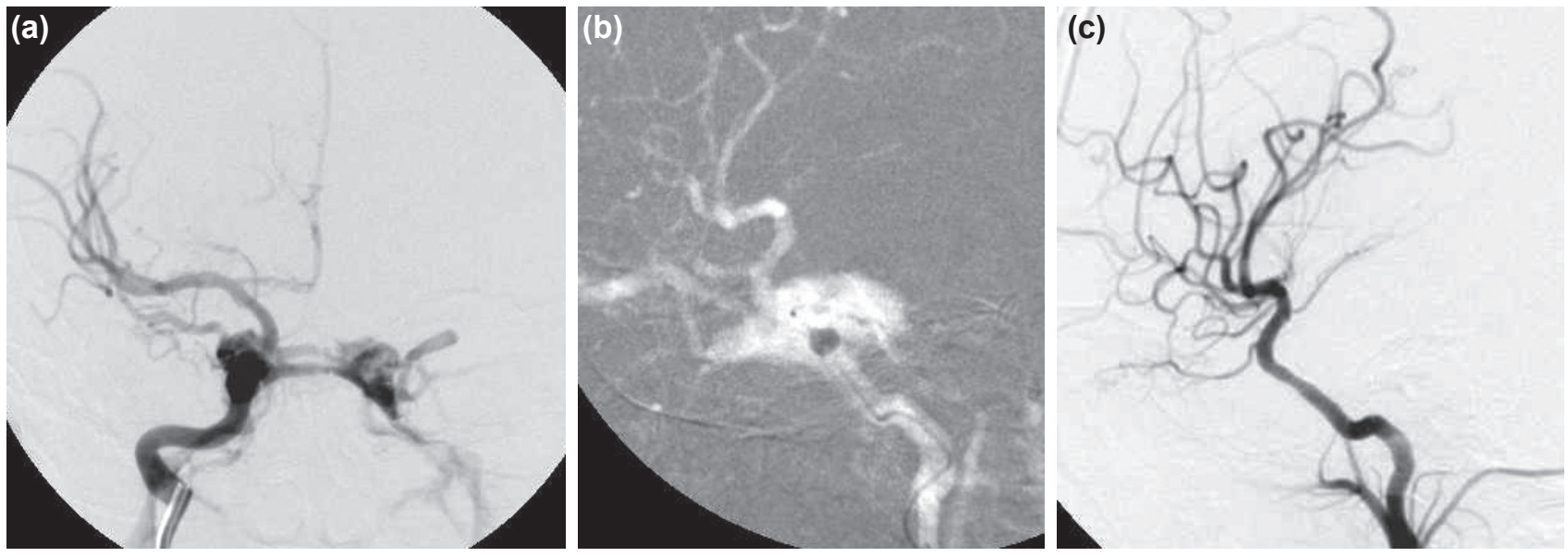

Figure 2. Case 3; (a) Preoperative right carotid angiogram in anteroposterior view demonstrates the carotid-cavernous fistula. (b) Lateral view of internal carotid angiogram obtained during attempted embolization with detachable balloon shows that the inflated balloon was not able to seal off the tear in the carotid artery and that residual fistula remains. (c) Lateral projection of carotid angiogram obtained after placement of two stent grafts shows elimination of the fistula and restoration of the flow in the right internal carotid artery. 

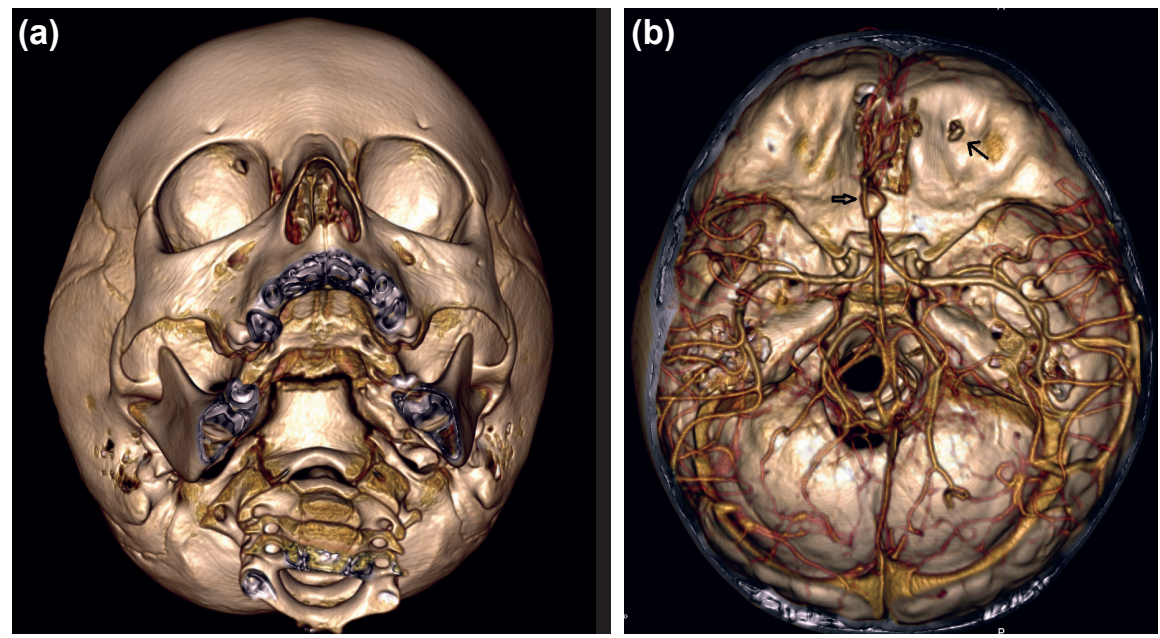

(c)

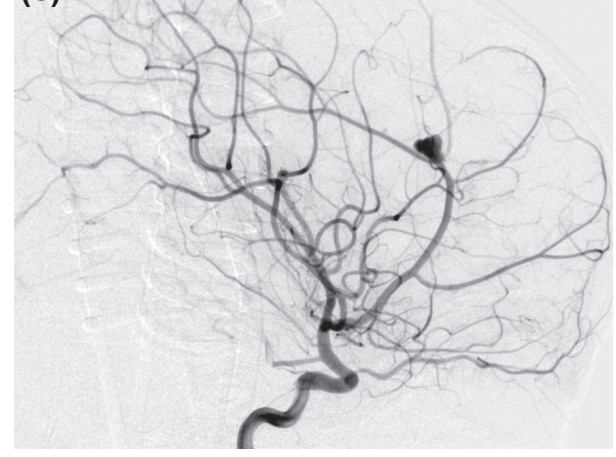

(d)

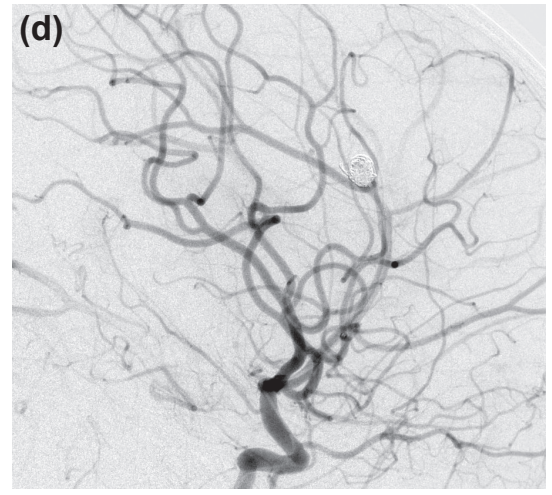

Figure 3. Case 5; (a) Base view obtained from 3D rendering of head CT reveals a focal bony defect of the medial aspect of the orbital roof which corresponds to the entry point of the knitting needle to the cranium. (b) 3D rendering of the CTA demonstrating the defect of the orbital roof (arrow) and the aneurysm (open arrow) as seen from above. (c) Lateral view of right internal carotid angiogram shows the distal anterior cerebral artery traumatic aneurysm. (d) Lateral view of the right internal carotid angiogram after endovascular treatment reveals almost total obliteration of the aneurysm with coils. Due to the traumatic nature of the aneurysm, there was recurrence on follow-up, which was treated with endovascular parent artery sacrifice.

cant retroorbital headaches immediately after the accident which gradually worsened over the 3 months and converted to cephalalgia. A CT scan revealed a mass lesion of the middle cranial fossa. A CT angiogram showed the lesion to be a giant dissecting aneurysm of the proximal segment of middle cerebral artery. The aneurysm was treated by placement of Silk (Balt, Montmercy, France) flow diverter stents within a larger Leo (Balt, Montmercy, France) intracranial stent. 3-month CT angiogram demonstrated a patent middle cerebral artery and almost total occlusion of the aneurysm. The patient remained neurologically intact.

Case 5- A 2-year-old girl had an impalement injury to her right eye with a knitting needle. The needle entered the anterior cranial fossa by passing through the orbital roof. A CT scan revealed focal subarachnoid blood between the frontal lobes anteriorly and the entry site of the needle (Fig. 3a). She was neurologically intact and a decision was made to follow her closely without further intervention. Three days after the accident, she suddenly deteriorated. After a seizure, she developed drowsiness and left sided hemiparesis. A repeat $C T$ scan was significant for a newly developed $3 \mathrm{~cm}$ hematoma at the location of the previous subarachnoid hemorrhage. CTA revealed a $6 \mathrm{~mm}$ pseudoaneurysm of the distal anterior cerebral artery (Fig. 3b). The aneurysm was coiled (Figs. 3c, d), and then, the hematoma was evacuated surgically. At 2 months, there was recurrence of the pseudoaneurysm which was then treated with endovascular parent artery occlusion. There was no clinical sequela. The patient remained asymptomatic at 21 months after the accident without recurrence of the aneurysm on magnetic resonance angiography.

Case 6- A 27-year-old male was referred with complaints of headache, proptosis and redness of the right eye developing immediately after a gunshot injury through the inferomedial aspect of the contralateral orbit (Fig. 4a) without any globe injury. There was restriction of abduction and adduction of the right eye. The carotid angiogram obtained 35 days later 

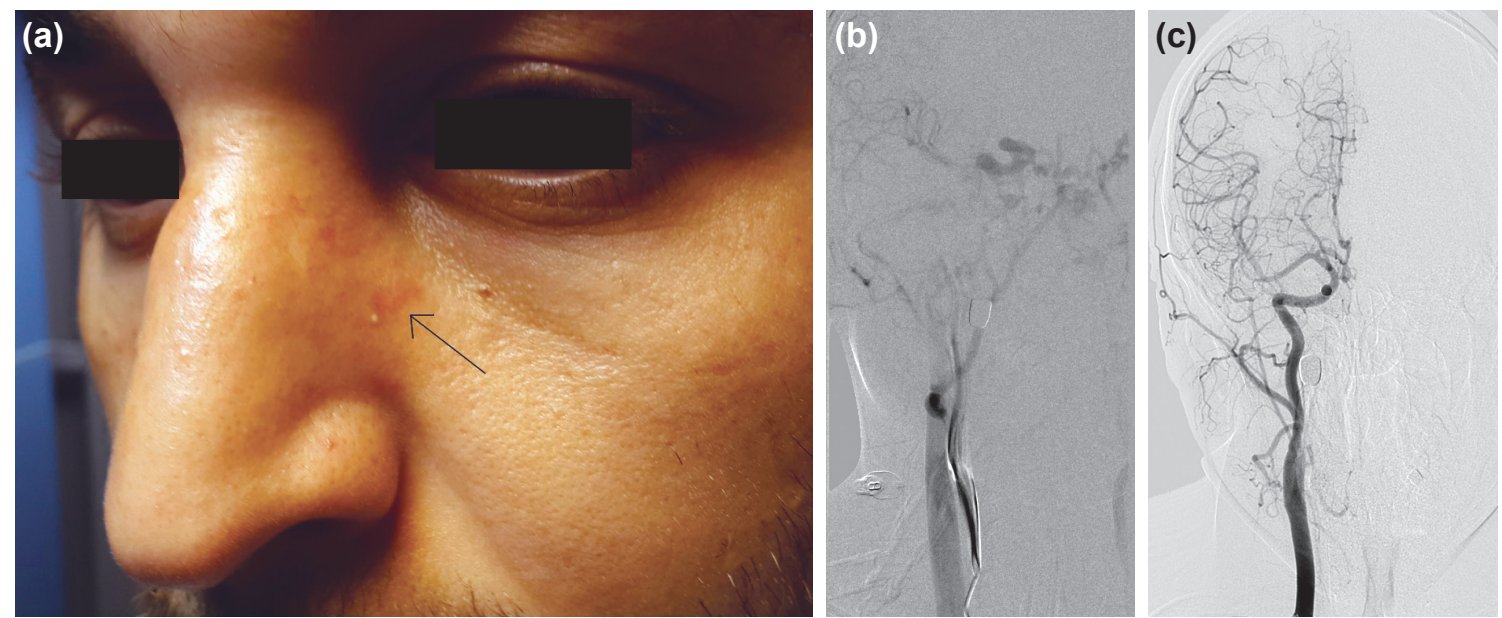

Figure 4. Case 6; (a) Photograph of patient 6 when he returned for a control angiogram 5 months after the injury and 4 months after treatment. The arrow marks the entry site of the bullet at the inferomedial rim of the left orbit which has healed with mild discoloration. (b) Pre-procedure right common carotid angiogram in right oblique projection shows simultaneous opacification of bilateral ophthalmic and angular veins secondary to the carotid-cavernous fistula as well as the internal carotid circulation arteries. Noted is the bullet that has traversed to the right. (c) Follow-up right common carotid angiogram 4 months after treatment in anteroposterior view shows no evidence of residual fistula and patency of the stent graft in the internal carotid artery.

revealed a right sided traumatic CCF (Fig. 4b), which was treated with 2 covered stents (Jostent Graftmaster Abbott Vascular Inc, CA, USA). The first stent opened more distally than anticipated and to cover the proximal leak into the fistula a second one was placed. There was immediate occlusion of the fistula. At 4 months, the internal carotid artery was patent, the fistula was obliterated and the patient was asymptomatic (Fig. 4c).

\section{DISCUSSION}

Vascular complications of penetrating brain injury include traumatic aneurysms, traumatic occlusions, subarachnoid hemorrhage, vasospasm, and traumatic fistulas. ${ }^{[0,18]}$ According to the recently published large series on vascular complications of penetrating head injury by Bodanapally et al.,"[13] true incidence of vascular injuries after penetrating head injury is not clearly known because this condition is associated with a high rate of mortality before patients are able to receive medical care. These authors state that the incidence among survivors ranges from 3 to $42 \%$, and they emphasize that previous reports mainly focus on the aneurysms. Despite the contradicting epidemiologic and etiologic data about these aneurysms, ${ }^{[19]}$ it is put forward that among all intracranial aneurysms, only 0.4 to 0.7 percent are traumatic and only one fifth of these traumatic aneurysms are secondary to penetration of the head. ${ }^{[18]}$ The incidence of cavernous fistula secondary to penetrating head injury is even more obscure and appears to be even lower compared to aneurysms. ${ }^{[12,20,21]}$

Periorbital penetrating trauma accounts for 30 to $50 \%$ of eye trauma, ${ }^{[22]}$ but the penetrating object usually does not reach the brain. The occurrence of transorbital penetrating brain injury is, therefore, uncommon. ${ }^{[6]}$ On the other hand, it is rare to encounter traumatic vascular injury after any kind of penetrating brain injury ${ }^{[19]}$ so it is ostensible that TIPVI is very rare. As a matter of fact, in a series of 35 patients with penetrating orbitocranial gunshot injuries, no vascular injury has been noted. ${ }^{[23]}$ In another study reviewing non-missile orbitocranial penetrations, only one case of a CCF and no aneurysms have been found. ${ }^{[2]}$ Turbin et al. reviewed all cases of low-velocity TIPIs from 1980 to 2002 and could not find any traumatic aneurysms in the literature. ${ }^{[2]} \mathrm{CCF}$ appears to be rare but still more common compared to aneurysms after TIPI. To date, some CCF cases have been reported secondary to TIPI. ${ }^{[10,17,24-26]}$

The most comprehensive studies on TIPI include a book by Van Duinen published in $2000^{[10]}$ and a thesis by Welman presented in $2004{ }^{[17]}$ It is quite likely that TIPI cases are included in large series of penetrating cranial trauma, ${ }^{[12,27]}$ but a distinct transorbital route is not defined in these large series. We went over the citations provided by Van Duinen ${ }^{[10]}$ and Welman et al. ${ }^{[17]}$ to search for the traumatic aneurysms secondary to low-velocity TIPI, and then, we also searched the literature from 1999 to date to find additional cases of low velocity TIPVI. We were able to identify only 15 documented cases during the last two centuries since the early 1800 s. $[10,17,19,28-30]$ Interestingly, in four of these 14 cases, the anterior cerebral artery was involved, the internal carotid artery/anterior choroidal artery was involved in 4 , we were not able to ascertain the exact location of the aneurysms in 7 cases from the data available. As for high velocity injury, we were able to identify only four cases of intracranial aneurysms/transections secondary to high velocity TIPI since 1999. ${ }^{[31-34]}$ All were "centrally" located; one on the anterior cerebral artery, two 
on basilar artery and one on MI segment of middle cerebral artery. All the vascular locations listed above are "central" (that is to say close to midline) in location. This is contrary to the more commonly encountered "peripheral" location of vascular injury secondary to $\mathrm{PHI}$ in general. ${ }^{[19]}$ In this series, all of the vascular injuries were central (internal carotid, anterior cerebral, proximal middle cerebral).

The three most frequent trajectories by which foreign objects penetrate the brain are through the orbital roof, the superior orbital fissure, or the optic canal. ${ }^{[5,6]}$ The most frequent path is via the roof of the orbit since the superior orbital plate of the frontal bone is fragile, and during the injury, patients extend their heads backwards, exposing the orbital roof. The next most common route is via the superior orbital fissure. The objects that enter the orbit at a low velocity are directed by the bony anatomy toward the superior orbital fissure. $A$ third trajectory of penetration is the optic canal. ${ }^{[5,6]}$ Penetrating objects may have been directed centrally because of the funneling of low-velocity objects centrally as they can make their way into the skull through the low-resistance pathways mentioned above.

Superior orbital fissure penetration is more likely to result in lesions around cavernous sinus, ${ }^{[28]}$ which are represented by cavernous sinus thrombosis or rarely carotid-cavernous fistula and very rarely, isolated cavernous aneurysms. In our literature search, we found reports on cavernous sinus thrombosis, ${ }^{[2]}$ scattered reports on CCFs ${ }^{[17,10,24-26]}$ and a scant number of ICA aneurysms around the cavernous portion of the $I C A^{[10]}$ secondary to TIPI. We are unaware of the occurrence of a case, regardless of the type or site of the trauma, similar to the one we presented in which there were coalescing aneurysms of the cavernous ICA secondary to multi-hole penetration of the ICA (Case 2). We think that cavernous sinus thrombosis secondary to the indwelling pellets concealed the multiple vessel wall defects of the ICA within the cavernous ICA, and as the thrombus around these defects resolved, there was coalition of the pseudoaneurysms within the sinus. Another interesting fact about this case was the presence of an asymptomatic small cerebral infarction in the distal cerebrovascular territory. Occurrence of cerebral infarcts as a sequela to penetrating ICA injury has been reported rarely in the literature. ${ }^{[35,36]}$

The clinical importance of TIPVI arises from the following: I) The orbit is a pathway for low-velocity, small-sized objects to reach the brain, which was the case in five out of six patients in our series, and in three of these, the penetrating pen or knitting needle would be unlikely to enter the brain had the injury occurred in other parts of the skull. The effect of this low-energy injury may appear to be deceivingly local. ${ }^{[2]}$ Again in five out of six of our cases, findings were confined to the orbitofacial region concealing the underlying vascular brain injury. At times, even the orbitofacial entry wounds of sizable penetrating objects may be missed in TIPI. ${ }^{[2,37,38]}$ Furthermore, the globe, not uncommonly, is pushed sideways and the presence of vision as noted in some of our patients may provide false relief. 2) The incidence of vascular injury in TIPI may be too low for the emergency medicine physician or the ophthalmologist to bring to mind. 3) Cerebral arteries have very thin adventitia and no internal elastic lamina. Consequently, initially small traumatic pseudoaneurysm may quickly enlarge, rupture and re-rupture in 30 to $50 \%$ of cases causing mortality or significant morbidity. That is to say, TIPVI is a morbid injury without a straightforward diagnosis.

High-velocity objects like bullets tend to transect the vessels, and low-velocity penetrating injury is more likely to result in traumatic intracranial aneurysms. ${ }^{[33]}$ Either high-velocity impacts or the secondary occlusion and/or dissection of vessels are more straightforward to diagnose. Since low-velocity objects can reach the cerebral vessels relatively easily through the orbit, a high index of suspicion is needed for detection of traumatic intracranial aneurysms due to low-velocity penetrating trauma. These lesions are insidious, ${ }^{[19]}$ may result in the so called "talk and die" type of injury ${ }^{[22]}$ or tend to rupture later in the subacute phase or even go into chronic phase undetected. Cases 2 and 5 are examples of enlarging/rupturing traumatic intracranial aneurysms, Case I is an example that was followed into the chronic phase.

The suggested management of TIPI is to leave the penetrating object in situ and immediately transfer the patient to a trauma or tertiary care center. ${ }^{[I]}$ It was reported to be unsafe and unnecessary to delay vascular imaging in these cases. ${ }^{\left[{ }^{2}\right]}$ Although TIPVI is not common after TIPI, detecting a vascular injury would be life-saving. We believe that given the widespread availability of multislice CT imaging, TIPI patients should undergo a cerebral CT angiogram in addition to a routine non-contrast head CT. Despite the fact that CT angiogram lacks the sensitivity of the digital subtraction angiogram (DSA), its ability to detect traumatic intracranial aneurysms is very accurate. ${ }^{\left[{ }^{13]}\right.}$ Risk factors for vascular injury include orbitobasal (including transorbital) entry site, subarachnoid or intraventricular hemorrhage, trajectory within $2 \mathrm{~cm}$ or less to the Circle of Willis ${ }^{[13]}$ and blast injury with Glascow Coma Scale 8 or less. ${ }^{[39]}$ These findings should prompt a DSA. Based on our case and our literature review, there appears a vulnerability of central arteries in TIPI. These arteries are the anterior cerebral, internal carotid, basilar and proximal middle cerebral arteries which should be well scrutinized on vascular imaging.

There is no standard treatment for TIPVI. Surgical and endovascular treatments and in selected cases, conservative management have been utilized. ${ }^{[19,39,40]}$ We managed one aneurysm conservatively because the patient was not compliant with her medications including antiplatelet drugs. Selective coiling had failed and the tiny cavernous aneurysm had diminished in size during follow-up. Otherwise, for the most part, interventional treatment of cavernous injuries is endovascular. In this arterial 
segment, various endovascular techniques including selective occlusion with balloons or coils, placement of stents or stent grafts have been utilized for the treatment of non-traumatic lesions or those due to blunt trauma. ${ }^{[19,40,41]}$ We found only one case of TIPVI treated endovascularly ${ }^{[19]}$ but expected that favorable results obtained in other traumatic aneurysms will also hold true for TIPVI. The traumatic aneurysms within the subarachnoid space have been managed either surgically or endovascularly. ${ }^{[39,19]}$ As a traumatic cerebral aneurysm lacks an aneurysm wall and is actually a pseudoaneurysm confined by the surrounding subarachnoid clot, conventional clipping or coiling is associated with re-rupture or a high rate of recurrence. ${ }^{[39]}$ Whenever feasible, we prefer to perform endovascular parent artery occlusion for these aneurysms. With improvements in stent technology, smaller stents and flowdiverter stents are available. These devices allow for the healing of the aneurysmal wall defect over the stent struts even in very fragile, dissecting type aneurysms ${ }^{[42]}$ and decrease the rate of recurrences. We used a flow diverter in one of our patients and believe these devices will be used more frequently in traumatic intracranial aneurysms in the future.

One point to underscore is that repeat vascular imaging is critical in the management of TIPVI and other traumatic intracranial aneurysms. We suggest performing a repeat CT angiogram or DSA after an initially negative imaging study in high risk patients, which enables the physician to catch the aneurysms that had been concealed by the initial vasospasm or that had demonstrated interval growth. Regardless of the treatment modality employed, repeat vascular imaging is critical to detect recurrences in these lesions which are prone to recur without significant signs or symptoms.

TIPVI is a rare but devastating complication of TIPI. Since low velocity injury may cause intracranial penetration and vascular damage without significant symptoms or findings, a high level of suspicion is needed to detect TIPVI. Vascular imaging should be used liberally in cases of TIPI. Transcatheter angiographic techniques allow for both unequivocal diagnosis and also treatment of TIPVI with good results.

Conflict of interest: None declared.

\section{REFERENCES}

1. Gennarelli TA, Champion HR, Sacco WJ, Copes WS, Alves WM. Mortality of patients with head injury and extracranial injury treated in trauma centers. J Trauma 1989;29:1193-202. CrossRef

2. Turbin RE, Maxwell DN, Langer PD, Frohman LP, Hubbi B, Wolansky $\mathrm{L}$, et al. Patterns of transorbital intracranial injury: a review and comparison of occult and non-occult cases. Surv Ophthalmol 2006;51:449-60.

3. Skoch J, Ansay TL, Lemole GM. Injury to the Temporal Lobe via Medial Transorbital Entry of a Toothbrush. J Neurol Surg Rep 2013;74:23-8.

4. Amirjamshidi A, Abbassioun K, Roosbeh H. Air-gun pellet injuries to the head and neck. Surg Neurol 1997;47:331-8. CrossRef

5. Schreckinger M, Orringer D, Thompson BG, La Marca F, Sagher O.
Transorbital penetrating injury: case series, review of the literature, and proposed management algorithm. J Neurosurg 2011;114:53-61. CrossRef

6. Balasubramanian C, Kaliaperumal C, Jadun CK, Dias PS. Transorbital intracranial penetrating injury-an anatomical classification. Surg Neurol 2009;71:238-40. CrossRef

7. Kitakami A, Kirikae M, Kuroda K, Ogawa A. Transorbital-transpetrosal penetrating cerebellar injury--case report. Neurol Med Chir (Tokyo) 1999;39:150-2. CrossRef

8. Civelek E, Bilgiç S, Kabataş S, Hepgül KT. Penetrating transorbital intracranial foreign body. [Article in Turkish] Ulus Travma Acil Cerrahi Derg 2006;12:245-8.

9. Paiva WS, Monaco B, Prudente M, Soares MS, de Amorim RL, de Andrade AF, et al. Surgical treatment of a transorbital penetrating brain injury. Clin Ophthalmol 2010;4:1103-5. CrossRef

10. Martin Th A van Duinen, editor. The transorbital intracranial penetrating injury: a review of the literature from a neurosurgical viewpoint. Boston: Kluwer Academic Publishers, 163. p. 2000.

11. Lin HL, Lee HC, Cho DY. Management of transorbital brain injury. J Chin Med Assoc 2007;70:36-8. CrossRef

12. du Trevou MD, van Dellen JR. Penetrating stab wounds to the brain: the timing of angiography in patients presenting with the weapon already removed. Neurosurgery 1992;31:905-12. CrossRef

13. Bodanapally UK, Shanmuganathan K, Boscak AR, Jaffray PM, Van der Byl G, Roy AK, et al. Vascular complications of penetrating brain injury: comparison of helical CT angiography and conventional angiography. J Neurosurg 2014;121:1275-83. CrossRef

14. Chen PY, Yao SF, Dai AX, Chen HJ, Wang KW. A shocking craniofacial penetrating injury by a steel bar. Ulus Travma Acil Cerrahi Derg 2014;20:382-4. CrossRef

15. Erkutlu I, Alptekin M, Dokur M, Geyik M, Gök A. Unusual penetration of a construction nail through the orbit to the cranium: a case report. Ulus Travma Acil Cerrahi Derg 2011;17:79-82. CrossRef

16. Perez EA. Penetrating Trauma. In: Bucholz RW, Heckman CD, CourtBrown CM, editors. Rockwood and Green's Fractures in Adults. 6th ed. Philadelphia: Lippincott Williams \& Wilkins; 2006. p. 446-75.

17. Welman C. A review of the Groote Schuur hospital experience of lowvelocity non-missile penetrating orbital and transorbital stab wounds [dissertation]. University of Cape Town, 2004.

18. Vascular complications of penetrating brain injury. J Trauma 2001;51(2 Suppl):26-8.

19. Cohen JE, Gomori JM, Segal R, Spivak A, Margolin E, Sviri G, et al. Results of endovascular treatment of traumatic intracranial aneurysms. Neurosurgery 2008;63:476-86. CrossRef

20. Fields CE, Cassano AD, Dattilo JB, Yelon JA, Ivatury RR, Broderick TJ. Indirect carotid-cavernous sinus fistula after shotgun injury. J Trauma 2000;48:338-41. CrossRef

21. Fabian TS, Woody JD, Ciraulo DL, Lett ED, Phlegar RF, Barker DE, et al. Posttraumatic carotid cavernous fistula: frequency analysis of signs, symptoms, and disability outcomes after angiographic embolization. J Trauma 1999;47:275-81. CrossRef

22. Erkol Z, Bilal S, Bayram M. An orbitocranial penetration case with a perforating body. [Article in Turkish] Ulus Travma Acil Cerrahi Derg 1996;2:47-50.

23. Gönül E, Erdoğan E, Taşar M, Yetişer S, Akay KM, Düz B, et al. Penetrating orbitocranial gunshot injuries. Surg Neurol 2005;63:24-31.

24. Chibbaro S, Tacconi L. Orbito-cranial injuries caused by penetrating non-missile foreign bodies. Experience with eighteen patients. Acta Neurochir (Wien) 2006;148:937-42. CrossRef

25. Zimmer J, Kido DK, Rumbaugh CL. Orbital gunshot wound causing a 
carotid-cavernous fistula and ipsilateral occlusion of the internal carotid artery: case report. Mil Med 1979;144:485-6.

26. Khalil N, Elwany MN, Miller JD. Transcranial stab wounds: morbidity and medicolegal awareness. Surg Neurol 1991;35:294-9. CrossRef

27. Bodanapally UK, Saksobhavivat N, Shanmuganathan K, Aarabi B, Roy AK. Arterial injuries after penetrating brain injury in civilians: risk factors on admission head computed tomography. J Neurosurg 2015;122:21926. CrossRef

28. Kim MS, Sim SY. Traumatic aneurysm of the callosomarginal arterycortical artery junction from penetrating injury by scissors. J Korean Neurosurg Soc 2014;55:222-5. CrossRef

29. Kawata H, Ohba M, Hikage F, Ohguro H. Transorbital cerebral injury in two children. Jpn J Clin Ophthalmol 2009;63:665-9.

30. Greene KA, Dickman CA, Smith KA, Kinder EJ, Zabramski JM. Selfinflicted orbital and intracranial injury with a retained foreign body, associated with psychotic depression: case report and review. Surg Neurol 1993;40:499-503. CrossRef

31. Tokdemir M, Türkçüoğlu P, Kafadar H, Türkoğlu A. Sudden death following periorbital pellet injury. Brain Inj 2007;21:997-9. CrossRef

32. Brenke C, Fontana J, Schmieder K, Barth M. Surgical management of basilar artery laceration caused by transorbital penetrating injury: case report. J Neurol Surg A Cent Eur Neurosurg 2013;74 Suppl 1:239-41.

33. Horowitz MB, Kopitnik TA, Landreneau F, Ramnani DM, Rushing EJ, George E, et al. Multidisciplinary approach to traumatic intracranial aneurysms secondary to shotgun and handgun wounds. Surg Neurol 1999;51:31-42. CrossRef

34. Barua NU, Ross AH, Sandeman DR. Traumatic callosomarginal aneu- rysm following orbital gunshot wound in a 16-year-old girl. Br J Neurosurg 2007;21:237-8. CrossRef

35. Hiraishi T, Kawaguchi T, Kobayashi T, Tomikawa M, Ito Y, Fujii Y. Unstable stenosis of the internal carotid artery caused by a craniofacial nailgun injury-case report-. Neurol Med Chir (Tokyo) 2009;49:590-3.

36. Song JK, Srinivasan J, Gordon DS, Newell DW, Baxter AB. Internal carotid pseudoaneurysm and cerebral infarction from shotgun pellet penetration and embolization. AJR Am J Roentgenol 1999;173:1116.

37. Abdelaziz L, Barbara R, Scullion D, Cosgrave E, Metcalfe T. A minor lid laceration concealing a potentially life-threatening injury. BMJ Case Rep 2012. CrossRef

38. Vaqas B, Kopniczky Z, Haliasos N, Namnyak S, Pollock J. An occult intracranial foreign body introduced via a conjunctival wound. Trauma 2013;15:252-6. CrossRef

39. Bell RS, Vo AH, Roberts R, Wanebo J, Armonda RA. Wartime traumatic aneurysms: acute presentation, diagnosis, and multimodal treatment of 64 craniocervical arterial injuries. Neurosurgery 2010;66:66-79. CrossRef

40. Fulkerson DH, Voorhies JM, McCanna SP, Payner TD, Leipzig TJ, Scott JA, et al. Endovascular treatment and radiographic follow-up of proximal traumatic intracranial aneurysms in adolescents: case series and review of the literature. Childs Nerv Syst 2010;26:613-20. CrossRef

41. Archondakis E, Pero G, Valvassori L, Boccardi E, Scialfa G. Angiographic follow-up of traumatic carotid cavernous fistulas treated with endovascular stent graft placement. AJNR Am J Neuroradiol 2007;28:342-7.

42. Aydin K, Arat A, Sencer S, Hakyemez B, Barburoglu M, Sencer A, et al. Treatment of ruptured blood blister-like aneurysms with flow diverter SILK stents. J Neurointerv Surg 2015;7:202-9. CrossRef

\section{ORIJINAL ÇALIŞMA - ÖZET}

\section{Transorbital penetran intrakraniyal travmaların serebrovasküler komplikasyonları}

\section{Dr. Yonca Ozkan Arat, ${ }^{1,2}$ Dr. Anil Arat, ${ }^{3}$ Dr. Kubilay Aydın ${ }^{4}$}

\section{'Başkent Üniversitesi Tıp Fakültesi, Göz Hastalıkları Anabilim Dalı, Ankara}

${ }^{2}$ Wisconsin Üniversitesi, Göz Hastalıkları ve Görme Bilimleri Bölümü, Madison, WI, ABD

${ }^{3}$ Hacettepe Üniversitesi Tıp Fakültesi, Radyoloji Anabilim Dalı, Girişimsel Nöroradyoloji Birimi, Ankara

${ }^{4}$ Istanbul Üniversitesi İstanbul Tıp Fakültesi, Radyoloji Anabilim Dalı, Girişimsel Nöroradyoloji Birimi, İstanbul

AMAÇ: Transorbital intrakraniyal penetran travmayı takiben gelişen serebrovasküler travma (TIPVT) nadirdir. Bu olgularda ilk muayene tablosunun göreceli olarak hafif olması altta yatan ve yaşamsal tehlikesi olan vasküler travmayı maskeleyebilir. Bu çalışmada amacımız, TIPVT olgularını ve endovasküler tedavi sonuçlarımızı incelemektir.

GEREÇ VE YÖNTEM: Subakut veya kronik fazda anjiyografik olarak dokümente edilmiş altı TIPVT olgusu geriye dönük olarak incelendi. Altı hastanın beşinde endovasküler tedavi uygulandı, bir olguda endovasküler tedavi denendi ancak konservatif tedavi kararı verildi.

BULGULAR: Tam görme kaybı ve hafif inme sonrası tedaviye alınan bir hasta haricinde hiçbir hastada nörolojik kayıp izlenmedi. İki olguda karotikokavernöz fistül, üç olguda anterior serebral, orta serebral ve kavernöz karotis arter anevrizmaları, bir olguda tromboze kavernöz sinüs içinde koalisyon gösteren kavernöz anevrizmalar izlendi. Fistüller kaplı stentlerle, anevrizmalar parent arter oklüzyonu veya akım yönlendiricilerle tedavi edildi. Tüm hastalarda komplikasyonsuz bir iyileşme süreci izlendi.

TARTIŞMA: TIPVT olguları hafif görünen yanıltııı başvuru tablosundan sonra geç dönemde kendisini gösterebilir. Bu olguların atlanmaması için en küçük şüphede vasküler görüntüleme yapılmalıdır. Transkateter anjiyografik teknikler, TIPVT olgularının teşhisine olduğu gibi iyi sonuçlarla tedavisine de olanak sağlamaktadır.

Anahtar sözcükler: Serebrovasküler travma; fistül; penetran intrakraniyal travma; transorbital travma; travmatik anevrizma.

Ulus Travma Acil Cerrahi Derg 20I5;2I (4):27I-278 doi: 10.5505/tjtes.20I5.48839 